Revue d'histoire de l'Amérique française

REYUE D.HISTOIRE DE L'AMÉRIQUE FRANÇAISE

BOULET, Marcel et Jacques DUCHARME, Répertoire numérique

du Fonds de l'Institut agricole d'Oka (E 82). Service des Archives, Université de Montréal, 1978. 28 p. (Publication no 41).

\title{
Marcel Caya
}

Volume 33, numéro 4, mars 1980

URI : https://id.erudit.org/iderudit/303825ar

DOI : https://doi.org/10.7202/303825ar

Aller au sommaire du numéro

Éditeur(s)

Institut d'histoire de l'Amérique française

ISSN

0035-2357 (imprimé)

1492-1383 (numérique)

Découvrir la revue

Citer ce compte rendu

Caya, M. (1980). Compte rendu de [BOULET, Marcel et Jacques DUCHARME, Répertoire numérique du Fonds de l'Institut agricole d'Oka (E 82). Service des Archives, Université de Montréal, 1978. 28 p. (Publication no 41).] Revue d'histoire de l'Amérique française, 33(4), 602-603.

https://doi.org/10.7202/303825ar d'utilisation que vous pouvez consulter en ligne.

https://apropos.erudit.org/fr/usagers/politique-dutilisation/ 


\section{NOTES BIBLIOGRAPHIQUES}

BOULET, MARCEL et JACQUES DUCHARME, Répertoire numérique du Fonds de l'Institut agricole d'Oka (E 82). Service des Archives, Université de Montréal, 1978, 28 p. (publication no 41).

L'École d'agriculture d'Oka, fondée en 1893 par des Trappistes, était devenue l'Institut agricole en 1908 en s'affiliant à l'Université Laval de Montréal. L'enseignement qu'on y donnait était aussi théorique que pratique, puisque l'Institut possédait une ferme prospère dotée de champs de culture potagère, de pâturages permanents, de forêts, d'un cheptel et d'installations entièrement mécanisées. Son importance peut être mesurée par le rayonnement pédagogique, scientifique et intellectuel qu'il exerçait non seulement sur la région immédiate, mais sur l'ensemble de l'industrie agricole du Québec. L'Institut fut contraint de fermer ses portes en 1962 par suite d'une décision gouvernementale réservant à l'Université Laval l'enseignement de l'agronomie au Québec. 
Le Fonds de l'Institut agricole d'Oka que ce répertoire numérique décrit, comprend un total de 530 pièces portant sur la période 1920 à 1970 . Il est principalement constitué de documents administratifs. Extrêmement bien présenté, le répertoire offre en introduction un aperçu historique relatant les principales étapes de l'évolution de l'Institut et fournit par la suite des descriptions plus détaillées de chacune des séries documentaires, incluant les noms des personnes mentionnées ou des auteurs des documents. Un index de ces noms en accélère grandement la consultation. Conçu selon un modèle de plus en plus en vogue, ce guide a l'avantage de fournir assez de renseignements pour aider le chercheur intéressé à amorcer sa recherche sans avoir à consulter les répertoires plus détaillés. Il est regrettable que dans leurs descriptions de séries chronologiques de correspondance les auteurs n'aient pas crû bon d'ajouter aux noms de personnes, un bref aperçu des sujets abordés.

Service des Archives

Université McGill

MARCEL CAYA 